to biological treatment. CT can be considered as a useful biomarker of inflammation and predictor of response to treatment in AS.

References:

[1] Karkucak M, Kalkısım A, Kola M, et al. SAT0408 anti Tnf-a therapy provides beneficial effects on choroidal thickness increase in patients with active ankylosing spondylitis: a possible mechanism of infliximab effectiveness in suppressing uveitis attacks. Ann Rheum Dis. 2016;75:817.

Disclosure of Interests: None declared

DOI: 10.1136/annrheumdis-2020-eular.1397

\section{AB0727 WORK OUTCOMES AND ASSOCIATED FACTORS IN ANKYLOSING SPONDYLITIS PATIENTS IN CHINA}

L. Tu ${ }^{1}$, Y. Xie ${ }^{1}$, Q. Lv ${ }^{1}$, M. Yang ${ }^{1}$, Z. Liao ${ }^{1}$, S. Cao ${ }^{1}$, Q. Wei ${ }^{1}$, J. Gu$^{1} .{ }^{1}$ Third Affiliated Hospital of Sun Yat-Sen University, Rheumatology, Guangzhou, China

Background: Poorer work productivity due to pain and functional impairment is commonly seen in ankylosing spondylitis (AS) patients, which may contribute to huge social economic burden. However, data about work outcomes and associated factors in Chinese AS patients were barely reported.

Objectives: To assess work outcomes and identify factors associated with poor work productivity in patients with AS in China.

Methods: A cross-sectional study was conducted in China. Adult patients (aged $\geq 18$ years) fulfilled the 1984 New York modified criteria of AS were enrolled from rheumatology center from Jan 2017 to Aug 2017. All participants completed questionnaires about socio-demographic characteristics, disease characteristics, quality of life and the Work productivity and activity impairment questionnaire in AS (WPAI:SpA) to accesses the impact of chronic health conditions on job performance and productivity. Factors associated with work outcomes were evaluated.

Results: A total of 91 patients with AS were included: $87.8 \%$ males, $78.02 \%$ employed, mean age and disease duration of 30 and 10 years respectively. The mean (SD) activity impairment of all patients was $48.57 \%(22.02 \%)$. For patients with employed work, mean (SD) absenteeism, presenteeism and work productivity loss were $10.22 \%$ (19.44\%), 43.86\% (22.48\%) and 47.92\% (25.81\%) respectively. In multivariable analysis, activity impairment was associated with Bath Ankylosing Spondylitis Functional Index (BASFI) $(P<0.01)$ and Ankylosing Spondylitis Quality of Life (ASQoL) $(P<0.01)$. Absenteeism was associated with disease duration $(P=0.03)$. Presenteeism was associated with disease duration $(P=0.04)$, BASFI $(P<0.01)$ and ASQoL $(P<0.01)$. Work productivity loss was associated with BASFI $(P<0.01)$ and ASQoL $(P<0.01)$.

Conclusion: Longer disease duration, reduced physical function and poorer quality of life are associated with reduced work productivity in Chinese AS patients.

References:

[1] Boonen A, van der Heijde D, Landewe R, Spoorenberg A, Schouten H, Rutten-van Molken $\mathrm{M}$, et al. Work status and productivity costs due to ankylosing spondylitis: comparison of three European countries. Annals of the rheumatic diseases. 2002;61(5):429-37.

[2] Martindale J, Shukla R, Goodacre J. The impact of ankylosing spondylitis/ axial spondyloarthritis on work productivity. Best Pract Res Clin Rheumatol. 2015;29(3):512-23.

[3] Castillo-Ortiz JD, Ramiro S, Landewe R, van der Heijde D, Dougados M, van den Bosch F, et al. Work Outcome in Patients With Ankylosing Spondylitis: Results From a 12-Year Followup of an International Study. Arthritis Care Res (Hoboken). 2016;68(4):544-52.

[4] Sag S, Nas K, Sag MS, Tekeoglu I, Kamanli A. Relationship of work disability between the disease activity, depression and quality of life in patients with ankylosing spondylitis. J Back Musculoskelet Rehabil. 2018;31(3):499-505.

[5] Goh Y, Kwan YH, Leung YY, Fong W, Cheung PP. A cross-sectional study on factors associated with poor work outcomes in patients with axial spondyloarthritis in Singapore. Int J Rheum Dis. 2019;22(11):2001-8.

Disclosure of Interests: None declared

DOI: 10.1136/annrheumdis-2020-eular.1650

\section{AB0728 1 MICROVASCULAR CHANGES OF THE RETINA IN ANKYLOSING SPONDYLITIS, ANDTHE ASSOCIATION WITH CARDIOVASCULAR DISEASE - THE EYE FOR A HEART STUDY.}

R. Van Bentum ${ }^{1}$, M. Baniaamam ${ }^{1}$, B. Kinaci-Tas ${ }^{2}$, J. Van de Kreeke ${ }^{2}$, P. J. Visser ${ }^{3}$, E. Serné ${ }^{4}$, M. Nurmohamed ${ }^{1}$, I. Van der Horst-Bruinsma ${ }^{1}$ on behalf of -. 'Amsterdam UMC, Locatie VUmc, Rheumatology, Amsterdam, Netherlands; ${ }^{2}$ Amsterdam UMC, Locatie VUmc, Ophthalmology, Amsterdam, Netherlands; ${ }^{3}$ Amsterdam UMC, Locatie VUmc, Neurochemistry Laboratory and Biobank, Dpt. of Clinical Chemistry, Amsterdam, Netherlands; ${ }^{4}$ Amsterdam UMC, Locatie VUmc, Internal Medicine, Amsterdam, Netherlands
Background: Patients with ankylosing spondylitis (AS) have an increased risk at cardiovascular disease (CVD). Microvasculature changes might precede overt CVD, but have been poorly studied in AS. The small vessels of the retina are accessible for non-invasive visualization, and microvascular changes (retinal arteriolar narrowing, venular widening, loss of tortuosity) are described in association with CVD in other diseases.

Objectives: The aim of this study was to compare the retinal microvasculature of AS patients with healthy controls, and to assess gender differences.

Methods: A cross-sectional, case-control study comparing AS patients (fulfilling the modified New York criteria, Rheumatology outpatient clinic of Reade and Amsterdam UMC) with healthy controls (EMIF-AD PreClinAD cohort of the Dutch Twins Register(1)), men:women=1:1. Most important inclusion criteria were: age 50-75 years, diabetes mellitus was excluded. All subjects underwent Optical Coherence Tomography Angiography and fundus photography ( $\geq 1$ eye), analyzed with Singapore I Vessel Assessment software (Table 2). Differences between AS and controls were evaluated with generalised estimating equations (GEE), adjusted for demographics and cardiovascular risk, and stratified for gender.

Results: In total, 59 AS patients (mean disease duration 36 years) and 105 controls were included. Controls were significantly older than patients, but did not differ in cardiovascular profile (Table 1). Patients had a significantly lower retina arteriolar tortuosity $(\beta-0.1 ; p=0.02)$, and higher vessel density $(\beta 0.5, p=0.02)$, than controls (Table 2). Also, male AS patients showed a lower arteriovenula ratio compared to male controls $(\beta-0.03, p=0.04)$. There were no differences between women with and without AS. In AS, a high disease activity was associated with a wider (unfavorable) venular diameter $(p=0.05)$, whereas biologic use showed a wider (more favorable) arteriolar diameter $(p<0.01)$.

Conclusion: This study detected several retinal microvascular changes, in AS patients compared to controls, of which some are associated with CVD based on previous studies. Some changes were only observed in male-, but not in female, patients. A new finding was an increased capillary density in AS, of which the association with CVD-risk has not yet been studied before.

\section{References:}

[1] Konijnenberg E et al. The EMIF-AD PreclinAD study: study design and baseline cohort overview. Alzheimers Res Ther. 2018; 10:75.

Table 1. Patient characteristics AS $(n=57)$ and controls $(n=105)$

\begin{tabular}{|c|c|c|c|}
\hline & AS & Controls & $p$ \\
\hline Gender, women (\%) & $30(51)$ & $52(50)$ & ns \\
\hline Age, mean yrs (SD) & $60(6)$ & $68(4)$ & $<0.01$ \\
\hline Smoking currently, yes (\%) & $11(19)$ & $8(8)$ & 0.06 \\
\hline Body mass index, mean (SD) & $26(4)$ & $26(3)$ & ns \\
\hline Hypertension, yes (\%) & $23(39)$ & 39 (37) & ns \\
\hline Dyslipidemia, yes (\%) & $9(15)$ & $18(17)$ & ns \\
\hline Cardiovascular disease history, yes (\%) & $9(15)$ & $15(14)$ & ns \\
\hline NSAIDS (\%) & $24(41)$ & $6(6)$ & $<0.01$ \\
\hline Biological (mostly TNF inhibitor) ${ }^{\star}(\%)$ & $29(49)$ & $0(0)$ & $<0.01$ \\
\hline AS Disease Activity Score, mean (SD) & $2.1 \pm 0.9$ & & \\
\hline
\end{tabular}

Table 2. Retinal vascular parameters, differences AS and Control subjects

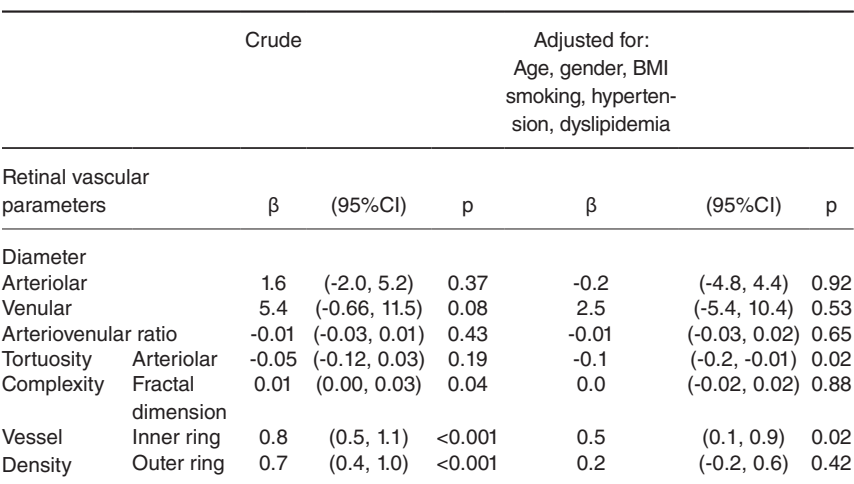

Disclosure of Interests: Rianne van Bentum: None declared, Milad Baniaamam: None declared, Buket Kinaci-Tas: None declared, Jacoba van de Kreeke: None declared, Pieter Jelle Visser: None declared, Erik Serné: None declared, Michae Nurmohamed Grant/research support from: Not related to this research, Consultant of: Not related to this research, Speakers bureau: Not related to this research, Irene van der Horst-Bruinsma Grant/research support from: AbbVie, Novartis, El Lilly, Bristol-Myers Squibb, MSD, Pfizer, UCB Pharma, Consultant of: AbbVie, Novartis, Eli Lilly, Bristol-Myers Squibb, MSD, Pfizer, UCB Pharma DOI: 10.1136/annrheumdis-2020-eular.4416 